\title{
The Distance Monitoring Tools Between the Ends of the Nozzle with the Workpiece for Gas Metal Arc Welding
}

\author{
Mohd Hasril Amiruddin, Sri Sumarwati
}

\begin{abstract}
Gas Metal Arc Welding (GMAW) is a welding process that combines an arc between the continuous electrode, which produces a mixing by heat generated by the arc melting the base metal electrodes. This process uses an inert gas as a protective element in the welding area. This study aims to analyze the welding quality level produced by students using the application in terms of monitoring the distance, angle, and speed between the ends of the nozzle with the workpiece for GMAW. In this study, one of the actual experimental designs used as the pretest and post-test design. The experimental group in this study was using distance monitoring tools, while the control group was using traditional teaching strategies that commonly used. The contents of the control group teaching were identical to the experimental group. The selected 22 respondents via purposive sampling consisted of students of the welding field, specifically metal fabrication. In this study, the research instrument used is through pre-test and post-test evaluation rubric. In this study, data were collected through a quantitative approach using Statistical Package for the Social Science (SPSS) version 22.0 software. The analysis of this study was carried out by conducting a descriptive analysis of data obtained by using statistics, such as per centage, mean, and standard deviation. Inference analysis was then performed to interpret the scores before and after treatment based on the test score data obtained in groups using the built-in distance monitoring tool. The inference statistics used in this study was two-way ANOVA. The findings of this study demonstrated the effectiveness of the distance estimation method by using distance monitoring tools between the ends of the nozzle and the workpiece for GMAW. This was attributable to the built-in distance monitoring tool, which could assist respondents in determining the proper distance between the ends of the nozzle and the workpiece to obtain a good and perfect welding result. Based on these results, there was a difference in the level of welding quality produced by the control and experimental groups.
\end{abstract}

Keywords: Welding Quality, Distance Monitoring Applications Tools; Nozzle; Gas Metal Arc Welding.

Revised Manuscript Received on February 05, 2020.

* Correspondence Author

Mohd Hasril Amiruddin. Faculty of Technical \& Vocational Education, Universiti Tun Hussein Onn Malaysia, Johor, Malaysia. Email: hasril@uthm.edu.my

Sri Sumarwati Faculty of Technical \& Vocational Education, Universiti Tun Hussein Onn Malaysia, Johor, Malaysia. Email: hasril@uthm.edu.my

(C) The Authors. Published by Blue Eyes Intelligence Engineering and Sciences Publication (BEIESP). This is an open access article under the CC BY-NC-ND license (http://creativecommons.org/licenses/by-nc-nd/4.0/)

\section{INTRODUCTION}

$\mathrm{T}$ he welding process is a process of incorporating a material with different materials, which involves the dilution process of a metal type to be made as a binder medium between a structure with another [1]. The welding process is very different from the soldering process, which simply melts the connecting material to establish a connection. Gas Metal Arc Welding (GMAW) is a welding process that combines the arc between a continuous electrode insert with a weld pool, which produces mixing by heat generated by the arc melting the base metal electrodes [2]. This process uses an inert gas as a protective element in the welding area. The basic concept of GMAW was first introduced and used in the 1920s, but it was rarely practical. From 1940 and onwards, welding of this type was widely used. At first, GMAW has been used to weld aluminium metal with the use of inert gas as a protective gas [3]. To reflect this, welding is thus termed as metal inert gas welding. When this process is carried out on various types of metals by using a gas mixture supplied separately, such as carbon dioxide (CO2). The use of metal gas arc welding for different welding works requires the use of a consumable uncoated electrode. Therefore, the weld pool must be protected by a protective gas. GMAW can be done via automatic or semiautomatic methods as shown in Fig. 1.

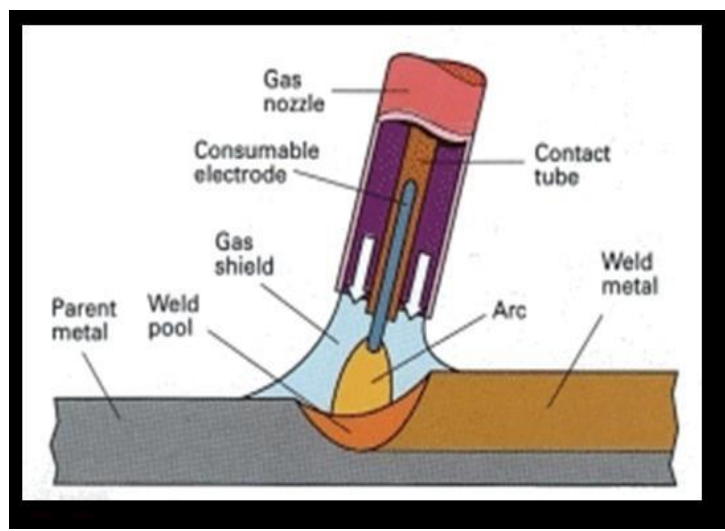

Fig. 1. Gas Protector Protecting the weld pool area

The factors that need to be controlled to ensure a good quality of welding are the angle, speed, and GMAW nozzle, so that factors stable and consistent during the welding process [4].

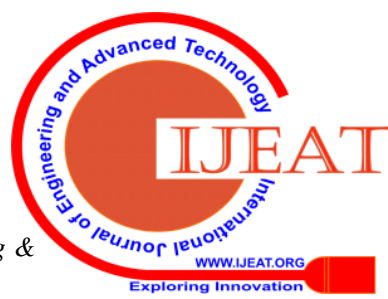


Currently, there is no monitoring method that is effective in helping a teacher or instructor and their student in terms of welding skills training monitoring for the angle, speed, and GMAW nozzle during welding work. According to [5], there is no efficient and systematic method to nozzle, especially with the workpiece during the GMAW process. [5] have also stated that arc distance is the distance between the ends of the metal core electrode with the workpiece surface, which arc published will be maintained at this distance. Distance arc that is too high will yield uneven welding mouldings, while the lack of transparency with this will result in defects in the weld.

The distance corresponding arc is between $5.0 \mathrm{~mm}$ to $6.0 \mathrm{~mm}$ of the workpiece. Therefore, this study is aimed to improve the quality of welding skills among students who followed the welding skills training for the GMAW process. Besides, this project will minimise the cost of welding errors or recurring training costs, as well as save time required during the training period. Through this application, the teacher or instructor can give feedback to students in improving the quality of welding by monitoring the stability of nozzle distance and consistency, and the speed and angle of welding, in comparison with the existing training methods. Furthermore, welding techniques in mastering other fundamental parameters are very important.

The distance of the arc is the distance between the ends of the electrodes and the workpiece, whereby the resulting arc can be maintained at such distance [6]. Excess arc spacing will cause unnatural welding by visual observation. The lack of conventional methods in measuring the distance between the tips of the nozzle in the corner of the weld material makes it difficult to identify and estimate the distance imposed during the welding process. Besides, the GMAW process is an electric arc welding process, which uses an electrode feed continuously and a protective gas is discharged to the nozzle for material protection [7]. The GMAW process requires major equipment to ensure the process runs perfectly in Fig. 2.

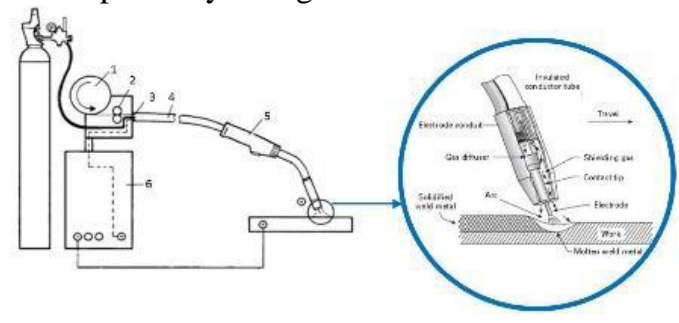

Fig. 2. GMAW Equipment [8]

Guidance Fig. 2:

(2) Drive rollers

(3) Flexible conduit

(4) Hose package

(5) Welding gun

(6) Power source [8]

The initial inventory by welders before undertaking the welding process is important as the process should be done following with procedures such as adjusting the voltage and wire speed accordingly [9]. The GMAW process can be done either manually, by using an interpreter weld, or semiautomatically, whereby the positioning control of the nozzle blowgun is fully controlled by the chief of the weld. The determine or monitor the angle, speed, and distance of

(1) Drum

main role of the power source is to provide the current and voltage required to maintain the arc and liquid metal transfer mechanism from the electrode to the weld pool. The supply of protective gas is to protect the arc from contaminants that are in the atmosphere and control the flow of the arc [10].

The wire nozzle unit is designed to supply the electrodes, and the role of wire nozzle is to provide the electrode feed through the nozzle at a speed that is automatically set by drive rollers [8]. Nozzle serves to drive the electrodes positioned correctly and control the flow of gas to the work area. Knowledge of parameter control is important to achieve a satisfactory weld quality standard as the parameters are closely related to each other. Therefore, changes to each parameter will affect other parameters. Skills and experience are required by the welder to control the parameters for each welding process.

The value of the welding quality is affected by the distance, angle, and speed the end of the nozzle. Therefore, a new method that can help in assessing these parameters is necessary. The GMAW process also requires experienced welders to produce perfect welding and prevent the occurrence of defects during the welding process. Several factors cause weaknesses in the quality of the welding material, whereby the lack of welding skills by welders is one of the main reasons. The failure of the welders to control the main parameters such as distance, angle and speed will cause a poor quality value. Defects that often occur in GMAW include the lack of fusion, lack of penetration, and spatter. Among other things, the skills of the welders in correcting and identifying the weld angle of the workpiece is also an obstacle due to the lack of appropriate methods in measuring the parameters applied during the welding process.

The position of different nozzles changes the shape of the arc and affects the heat circulation in the workpiece [11]. The appropriate angle in welding is from $70^{\circ}$ to $80^{\circ}$. According to The nozzle position welding affects the flow stream and causes plasma flow [11]. The effect of lacking experience by welders causes weaknesses. Besides, the competencies to apply the knowledge and skills for performing actions quickly and smoothly without errors in handling a variety of situations are very important [12]. Mistakes in applying knowledge and skills will produce welding of imperfect quality. Conventional methods need to be improved in line with the increase in technology to accelerate the process of upgrading the skills of the welders. The purpose of this study is to produce an application for monitoring the distance, angle, and speed between the ends of the nozzle with the workpiece for the welding process of GMAW in enhancing the effectiveness of welding training. To achieve the purpose of the study, the following objective has been developed:

i. Identify the level of quality of the weld produced by the control and experimental groups by using traditional methods for distance determination

ii. Identify the difference in welding quality level produced after post-test in the control and experimental groups? 


\section{METHODOLOGY}

Researchers generally use quantitative research, which is carried out to obtain facts by using objective measurement and statistical analysis of numerical data that understand and explain this study as a guide to researchers.

In an actual experimental design, several methods can be used to emulate all variables. By aligning the differences between respondents during sample selection, a pre-test is used as covariance.

The aim is to increase the sensitivity of covariance in testing the main effects and interactions by reducing the variance error [13]. The concept is explained in Table I.

Table-I: The experimental process

\begin{tabular}{|c|c|c|c|}
\hline Group & Pre-test & The dependent variable & Post-test \\
\hline PM & U1 & X1 & U2 \\
\hline PT & U1 & X2 & U2 \\
\hline
\end{tabular}

Guidance Table I:

$\mathrm{PM}=$ Groups using distance monitoring equipment (treatment)

$\mathrm{PT}=$ Groups using traditional methods (control)

$\mathrm{X} 1=$ New method using a distance monitoring tool

$\mathrm{X} 2=$ Traditional methods

$\mathrm{U} 1=$ Pre-measurement

$\mathrm{U} 2$ = Post-measurement

In this study, one of the actual experimental designs used as the pre-test and post-test, which used two measurements on the dependent variable before and after variables were manipulated [14]. The selected 22 respondents via purposive sampling consisted of students of the welding field, specifically metal fabrication. In this study, one of the actual experimental designs used as the pre-test and post-test design. The experimental group in this study was using distance monitoring tools, while the control group was using traditional teaching strategies that commonly used. The contents of the control group teaching were identical to the experimental group. The data obtained using the pre-test could detect less-skilled students to offer them initial help, while the post-test outputs were used to see any progress or weakness after an intervention.

Data were collected through a quantitative approach by using the Statistical Package for the Social Science (SPSS) version 22.0 software for descriptive and inferential statistical analysis. The researcher analyzed the data obtained from the evaluation rubric for pre-test and post-test using descriptive statistical methods, such as per centage, mean and standard deviation. Descriptive statistics focused on the collection, summarization, and characterization of a set of data. Descriptive statistics were used to describe the respondents' profile and explain the mean and standard deviation of the psychomotor performance data (skills) based on the independent variables of the study. Through descriptive statistics, it could also point out the difference in achievement between the two groups, while the inference statistics involved the t-test. Inference statistics is a test used to determine the difference or relationship between two mean independent variables measured by the ordinal scale, interval or ratio [14]. The statistical selection used in this study was based on the prescribed conditions of past studies and experts in statistics. Before the data were analyzed, the data included in SPSS software should be checked and cleaned (screening and cleaning). This was done to detect errors in inputting the data into SPSS. After that, the normality test of the data was checked to determine the normal data distribution. This prerequisite is important to allow parametric analysis such as t-test to be carried out. The normality of data distribution could be viewed through value and kurtosis.

\section{FINDINGS AND DISCUSSIONS}

This study involved two student groups, namely the control group and the experimental group. The variables of the study involved one variable, namely the method of determining the distance between the ends of the nozzle and the workpiece for the GMAW. The distance estimation method for the control group was traditional and the experimental group used the distance monitor. The descriptive analysis could only explain the mean differences and standard deviations for both groups. A total of 22 respondents were involved in this study to answer the study questions. The analysis of this study was carried out by conducting a descriptive analysis of the data obtained from the $1 \mathrm{G}$ position welding test set for pre-test and post-test welding using statistics, such as per centage, mean and standard deviation. Inference analysis was then performed to interpret the scores before and after treatment based on the test score data used in groups by using the built-in distance monitoring tool. The inference statistics used in this study were ANCOVA. This was followed by an analysis of data normality to ensure that univariate test requirements were met.

\begin{tabular}{|c|c|c|}
\hline \multirow{2}{*}{\multicolumn{2}{|c|}{$\begin{array}{ll}\mathrm{N} & \text { Valid } \\
& \text { Missing }\end{array}$}} & 11 \\
\hline & & 11 \\
\hline \multicolumn{2}{|c|}{ Mean } & 47.0000 \\
\hline \multicolumn{2}{|c|}{ Median } & 48.0000 \\
\hline \multicolumn{2}{|c|}{ Mode } & 40.00 \\
\hline \multicolumn{2}{|c|}{ Std. Deviation } & 9.96995 \\
\hline \multicolumn{2}{|c|}{ Variance } & 99.400 \\
\hline \multicolumn{2}{|c|}{ Skewness } & 251 \\
\hline \multicolumn{2}{|c|}{ Std. Error of Skewness } & 661 \\
\hline \multicolumn{2}{|c|}{ Kurtosis } & 193 \\
\hline \multicolumn{2}{|c|}{ Std. Error of Kurtosis } & 1.279 \\
\hline \multicolumn{2}{|c|}{ Range } & 36.00 \\
\hline
\end{tabular}

PRA E Valid
\begin{tabular}{|l|r|}
\hline \multicolumn{1}{|c|}{ Missing } & 11 \\
Mean & 11 \\
Median & 48.9091 \\
Mode & 50.0000 \\
Std. Deviation & $33.00^{2}$ \\
Variance & 9.70005 \\
Skewness & 94.091 \\
Std. Error of Skewness & 214 \\
Kurtosis & .661 \\
Std. Error of Kurtosis & 558 \\
Range & 1.279 \\
\hline
\end{tabular}

Fig.3. The analysis of normality
Published By:

Blue Eyes Intelligence Engineering \&

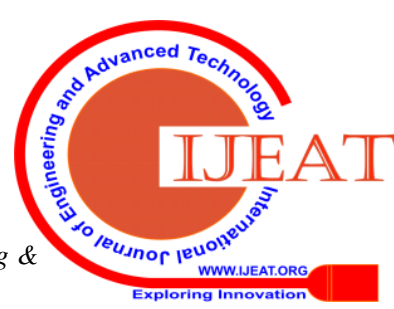


A. What is the level of quality of the weld produced by the control and experimental group using traditional methods for distance determination?

Table 2 shows the pre-test scores for the connection process in the control group by using the traditional method of determining the distance between the tip of the blowpipe with the workpiece for GMAW. In general, the mean pretest score to date position $1 G$ connection process for GMAW work in the control group $(\mathrm{n}=11)$ was 47 , with a standard deviation of 9.96995.

The minimum score for a pre-test for GMAW work in the control group was 30.00 , while the maximum score was 66.00. The overall mean score for the pre-test for GMAW work in the experimental group $(n=11)$ was 48.9091 , with a standard deviation of 9.70005. The minimum score for a pre-test in the experimental group was 33.00 and the maximum score was 66.00 .

Table-II: Pre-test scores in the control and experiment group

\begin{tabular}{|c|c|c|c|}
\hline $\begin{array}{l}\text { Pre-test score } \\
\text { control group }\end{array}$ & Quantity & $\begin{array}{l}\text { Pre-test score } \\
\text { experiment group }\end{array}$ & Quantity \\
\hline 30.00 & 1 & 33.00 & 1 \\
\hline 39.00 & 1 & 37.00 & 1 \\
\hline 40.00 & 1 & 41.00 & 1 \\
\hline 40.00 & 1 & 47.00 & 1 \\
\hline 43.00 & 1 & 48.00 & 1 \\
\hline 48.00 & 1 & 50.00 & 1 \\
\hline 49.00 & 1 & 51.00 & 1 \\
\hline 52.00 & 1 & 52.00 & 1 \\
\hline 53.00 & 1 & 53.00 & 1 \\
\hline 57.00 & 1 & 57.00 & 1 \\
\hline 66.00 & 1 & 66.00 & 11 \\
\hline Total & 11 & Total & 48.9091 \\
\hline Mean & 47.00 & Mean & 9.70005 \\
\hline SD & 9.96995 & SD & \\
\hline
\end{tabular}

Based on Tables 2, the overall level of GMAW quality produced by 11 students in the control and 11 students in the experimental groups, respectively, before being exposed to the method of using the distance monitoring device between the blowpipe and the workpiece for GMAW is very low. However, the mean score (mean $=48.9091$ ) for the experimental group was higher than in the control group (mean $=47,000$ ). The technique of determining the distance between the tip of the blowpipe with the workpiece was less effective when the respondents were more likely to use traditional methods to determine the distance. Therefore, they were not able to produce welding work properly. This is supported by [15], who stated that to achieve a selected activity, the techniques used should be effective and in line with the objectives of the activity. This is because the builtin distance monitoring tool can assist respondents in determining the proper distance between the ends of the nozzle and the workpiece to obtain a good and perfect welding result. Obtaining good welding results requires the distance between the electrode and the workpiece to be considered [1]. The absence of a tool to assist a person who

is new to a field of activity requiring techniques and skills is a significant factor for them to obtain good results in the activities [4].

B. Is there a difference in welding quality level produced by students after post-test in the control and experimental groups?

Referring to Table 3, the homogeneity of regression slopes based on *pre-test group shows significant values (sig. $=0.057$ ). Based on these significant values, the pre-test and post-test scores were not significant, with a significance of $p>0.05$ level. This indirectly indicates the variance value of all dependent variables across all groups in the independent variable.

Table-III: Homogeneity of Regression Slopes *pre-test groups

\begin{tabular}{|c|c|c|c|c|c|}
\hline Source & $\begin{array}{c}\text { Type III Sum of } \\
\text { Squares }\end{array}$ & $\mathrm{df}$ & Mean Square & $\mathrm{F}$ & Sig. \\
\hline $\begin{array}{c}\text { *pre-test } \\
\text { groups }\end{array}$ & 8.461 & 1 & 8.461 & 4.120 & .057 \\
\hline
\end{tabular}

R Squared $=.899$ (Adjusted R Squared $=.883$ )

In this study, Levene's test was used to test the variance of dependent variables across each group of independent variables in the study respondents. Based on Table 4, the results of Levene's test show a value (sig. $=0.051$ ) that is not significant, where the significance level is $\mathrm{p}>0.05$. Referring to the value (sig. $=0.051$ ) obtained, the variance of the dependent variables across each independent variable group in the study sample was similar. Based on the data obtained, the results of the study met the linearity requirements of the two-way ANOVA test (through variance and Levene test) and were analyzed using two-way ANOVA.

Table-IV: The results of Levene's test

\begin{tabular}{|c|c|c|c|}
\hline $\mathrm{F}$ & $\mathrm{df}_{1}$ & $\mathrm{df}_{2}$ & Sig. \\
\hline 4.311 & 1 & 20 & 0.051 \\
\hline
\end{tabular}

The results of this test shown in Table 5, indicate that the difference in welding quality level produced by students after post-test in the control and experimental groups.

Table-V: The results of two-way ANOVA tests

\begin{tabular}{|l|c|c|c|c|c|}
\hline Source & $\begin{array}{c}\text { Type III } \\
\text { Sum Of } \\
\text { Squares }\end{array}$ & df & $\begin{array}{c}\text { Mean } \\
\text { Square }\end{array}$ & $\mathrm{f}$ & Sig. \\
\hline $\begin{array}{l}\text { Corrected } \\
\text { Model }\end{array}$ & $330.485^{\mathrm{a}}$ & 3 & 110.162 & 53.636 & 0 \\
\hline Intercept & 3260.605 & 1 & 3260.605 & $1.59 \mathrm{E}+03$ & 0 \\
\hline Group & 3.186 & 1 & 3.186 & 1.551 & 0 \\
\hline Dimensi & 271.901 & 1 & 271.901 & 132.384 & 0 \\
\hline $\begin{array}{l}\text { Group } * \\
\text { Dimensi }\end{array}$ & 8.461 & 1 & 8.461 & 4.12 & 0 \\
\hline Error & 36.97 & 18 & 2.054 & & \\
\hline Total & 146660 & 22 & & & \\
\hline $\begin{array}{l}\text { Corrected } \\
\text { Total }\end{array}$ & 367.455 & 21 & & & \\
\hline \multicolumn{7}{|l|}{ R Squared $=.899$ (Adjusted R Squared =0.883) } \\
\hline
\end{tabular}

Table 5 shows the results of two-way ANOVA tests for the independent samples in 
this study show that there was a main effect of group independent variables $[\mathrm{F}(1,18)=1.551, \mathrm{p}<0.05]$ and dimensions $[\mathrm{F}(1,18)=132.384, \mathrm{p}<0.05$ against significant dimensional dependent variables. Also, the effect of interaction between the two independent variables (group * dimension) on the dependent variable was also significant $[\mathrm{F}$ $(1,18)=4.120, \mathrm{p}<0.05]$. The findings also indicate that the main effects and the interaction effects between the two independent variables accounted for 88.3 per cent of the change in the dependent variable. The results show that there a difference in welding quality level produced by students after post-test in the control and experimental groups.

This is based on the results of the study that shown in Table 5, which show the use of the distance monitoring tool between the ends of the nozzle and the workpiece for GMAW to improve the quality of welding produced. Based on the inference analysis performed, several tests were conducted to qualify for the inference statistical test, such as two-way ANOVA. The results of the two-way ANOVA below the sixth question indicated that the use of distance monitoring tool between the ends of the nozzle and the workpiece for GMAW in the control and experimental groups significantly affected the quality of welding produced by the respondents of the study.

This findings supported by [16], who states that for a given activity to succeed, the technique used must be effective and in line with the objective of the activity. Based on these results, there is a difference in the level of welding quality produced by students between the control and the experimental groups. Researchers report that differences in the method of determining the distance between the ends of the pile and the workpiece can influence the level of welding quality produced in a group. This statement is supported by [17], whose work has stated that the distance between the electrode and the workpiece is one of the factors that affect the welding quality produced. The findings of this study proved that the use of distance monitoring tools between the ends of the nozzle and the workpiece for GMAW affected the level of welding quality produced by the respondents for GMAW.

\section{CONCLUSION}

So these implications conclude that effective techniques and methods for determining the distance between the ends of the nozzle and the workpiece help a welder to obtain the desired welding quality level when doing Gas Metal Arc Welding (GMAW) work. The use of distance monitoring tools between the ends of the nozzle and the workpiece for the GMAW prompted the mason to focus more on the aspect of determining the distance between the end of the nozzle and the workpiece while doing the GMAW work.

The built-in distance monitoring tools provide many benefits in the welding industry, such as reducing the defects in GMAW, especially due to deficiencies as a result of the poor distance between the ends of the nozzle and the workpiece, thus reducing the cost of welding error. Besides, the use of time is also economical and does not interfere with the scheduling system of any operation that occurs in the industry.
The built-in distance monitoring tool has implications for UTHM students, especially students dealing with GMAW, which can improve their skills, especially GMAW skills, and to better understand the end of the nozzle with the workpiece to the welding quality produced. The findings showed a weakness in the quality of welding produced by the students in the welding and fabrication of Metal because determining the distance between the ends of the nozzle and the workpiece for the GMAW was more focused on traditional methods.

The exposure to using distance monitoring tools between the ends of the nozzle and the workpiece for GMAW while performing GMAW activities revealed a significant improvement. This study was restricted to UTHM students from the Faculty of Technical and Vocational Education of the Metal Welding and Fabrication (BBD) majors for Cohort 2 only, which merely observed the welding quality levels for GMAW work. Besides, these tools were more focused on distance-only aspects, and not on other aspects. As such, some suggestions for further research include, researchers may research actual welders in the welding industry using GMAW or study the differences between professional welders on the levels of achievement of welding quality produced.

\section{ACKNOWLEDGMENT}

The author would like to express appreciation to the Ministry of Higher Education is supporting this research through PPG VOT K011.

\section{REFERENCES}

1. Jeffus, L. Welding: Principles and Applications. 4th edition. Albany, N.Y.: Delmar Publishers, 2011.

2. Christena SB. Learn to weld: beginning GMAW welding and metals fabrication basics. 1st edition. Beverlly, U.S.A.: Quayside Publishing Group Reference, 2014.

3. Keifner JK. History of line pipe manufacturing in North America. 1st edition. Pensylvania: American Society of Mechanical Engineer (ASME); 2009.

4. Mishr, P. K. Welder Trade Theory. 1st edition. Mumbai, India. Upkars Prakashan Publishers, 2006.

5. Chen, S, \& Wu, J. Intelligentized methodology for arc welding dynamical process. Berlin: Springer, 2009.

6. Griffin, I. H. Basic Tig and Mig Welding: GTAW and GMAW. NY: Delmar Cengage Learning, 3Edition,1984.

7. Liu, X. Dual Bypass Gas Metal Arc Welding Process and Control 2008. University of Kentucky: Doctoral Dissertation.

8. Belinga, E. M. M. Applications and Benefit of Adaptive Pulsed GMAW. 2012. Lappeenranta University of Technology: Master Thesis.

9. Yacob, S. Evaluation of Weld bead Characterictics of AA6351 Welded Joints using Gas Metal Arc Welding Cold Metal Transfer (GMAW-CMT). University Tun Hussein Onn Malaysia: Master Thesis.

10. Campbell, S. W., Galloway, A. M. \& McPherson, N. A. GMAW Shielding Gas Optimisation by Refinement of Nozzle Geometry. The $8^{\text {th }}$ Pasific International Congress on Advance Materials and Processing, 2013, pp. 2131-2137.

11. Xiang, T., Li, H., Wei, H. L. \& Gao, Y. Arc Characteristic and Metal Transfer Behavior of Twin-Arc Integrated Cold Wire Hybrid Welding . International Journal Advance Manufacturing Technology, 2016, 87, pp. 2653-2663.

12. Byrd, A. P. Identifying the Effect of Human Factors and Training Methods on a Weld Training Program. IOWA State

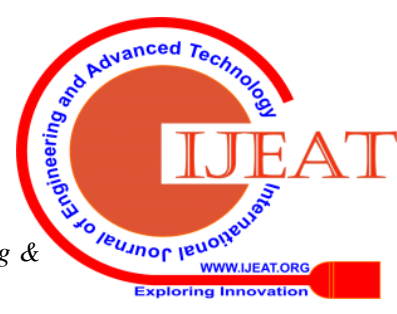


University: Doctoral Dissertation, 2014.

13. Green, J. Points of Intersection Between Randomixed Experiment And Quasi Experiment. Taeuber, C. The ANNALS of The American Academy Of Political And Social Science. U.S.A: American Academy of Political and Social Science. 2010, pp. 97111.

14. Chua, Y. P. Basics of Research Statistics. Kuala Lumpur: McGraw Hill Education, 2006.

15. John, L. S. Work Training: Competing in The New International Economy. Washington D.C., U.S. government printing office. 2010. pp, 129-131.

16. Chong, J. S. L.Use of CDROM Textbooks. Retrieved May 14, 2014 from http:eprints.oum.edu.my.pdf.

17. Rihar, G. Lack of Fusion in Welded Joints.Retrieved Mac 30, 2016, daripada

http://www.ndt.net/article/wcndt00/papers/idn403/idn403.html.

\section{AUTHORS PROFILE}

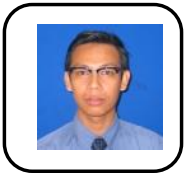

Mohd Hasril Amiruddin, is a senior lecturer in the Department of Engineering Education at the Faculty of Technical \& Vocational, Universiti Tun Hussein Onn Malaysia. He holds PhD from Universiti Kebangsaan Malaysia in technical and vocational education, in 2014, master's degree in education technology from Universiti Putra Malaysia and bachelor's degree in technical and vocational education from Universiti Tun Hussein Onn Malaysia. His research interest includes technical and vocational education training (TVET), indigenous people, entrepreneurship program, welding and engineering education.

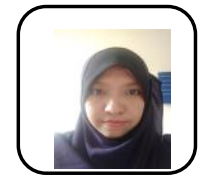

Sri Sumarwati, is a $\mathrm{PhD}$ student in Technical and Vocational Education, at the Faculty of Technical and Vocational Education from University Tun Hussein Onn Malaysia. She previously received her master degree from University Tun Hussein Onn Malaysia in technical and vocational education, in 2014 and a bachelor's degree in mathematics education from Universitas Ahmad Dahlan Indonesia. Her research interest includes technical and vocational education training (TVET), transferable skills, mathematics education, engineering education and entrepreneurship program. 